\title{
Scour properties of Mono Bucket foundation
}

\author{
I.-E. Stroescu \& P. Frigaard \\ Department of Civil Engineering \\ Aalborg University, Aalborg, Denmark
}

\begin{abstract}
Field experience proved that the Mono Bucket foundations (MBFs) have good response against scour development. Moreover, the ratio between large diameter (bucket lid) and the small diameter (shaft tower) is the driving parameter for the process of erosion/backfill, like scour protection diameter in the case of scour protected monopiles. However, the structural design to reduce the scour development for MBFs is still open to optimization. The influences of parameters that generate backfill and scour, the transfer load webs and the misalignment with seabed, have not been systematically studied until now. Thus, an experimental analysis was carried out to quantify the influence of webs, the misalignment parameters and combination of the two. The physical analysis uses the flume facility at Aalborg University. The test conditions are irregular waves superposition with co-directional or opposite tidal flow. Three structural models have been tested in several tidal cycles with a variation of the current intensity. Three levels of alignment with seabed are taken: one flushing and two more with different levels of misalignment. Field results for installation stage have been collected from the North Sea and compared with lab tests. The results showed a sensibility to the misalignment height comparable with the berm height of the scour protection on traditional monopiles leading to edge scour. Design improvements to limit the scour and increase backfill have been found. The experimental analysis compared with real surveys and existing studies showed good agreements. Scour protection based on collar solution shows high efficiency when scour protection should be required. The paper demonstrates good agreement between field measurements and small-scale studies. The unique value of the field measurements increases confidence in small-scale studies which are subject to scale and lab effects.
\end{abstract}

\section{INTRODUCTION}

The suction caisson technology is a competitive solution to the classic hammering approach of monopiles. The latter meets significant resistance from the environmental conditions due to ecological impact of vibrations and involves large costs for equipments and resources. The monopile on one hand is a simple technology that needs many added features to keep up with the wind turbine manufacturer requirements. The suction caisson is a complex technology that includes most of the additional monopile features. However, optimization is an ongoing process for both technologies.

For monopiles, the adjustable structural parameters are the plate thickness, diameter, length of hammering, transition piece and with/without scour protection. Additionally, monopiles use noise mitigation absorbent technology to face environmental installation limitations which are wrapped around the foundation - or hybrid hammering and vibration systems in sandy soils. Nevertheless, these solutions increase the cost for monopile foundations. Moreover, these add-on features are available only one way, for installation. The decommission process involves other machines to cut down the monopile at seabed level in best cases and leaving the steel used to fix foundation in soil.

For suction caisson the structural parameters for optimization are many more, they group between actual coffer and the part connecting to the wind turbine tower. The caisson can be optimized trough the plate thickness and geometry, shape of the caisson, diameter, fixing length in soil and reinforcement beams.

More features could be used to help during installation: 1) inner chambers are used for stability control and to increase suction pressure capacity; 2) nozzle spray system to reduce tip resistance for caisson's walls and level seabed at the plate level of caisson in sandy soil and 3) cyclic installation by reversing suction/pressure for clay soils.

The connection to wind turbine tower can be either a shaft or jacket piercing above sea level. The two solutions have adjustable parameters, the thickness of steel plate and diameter. The jacket type can also vary the number of legs and also the foundation 
caissons. The connection between suction caisson and the transfer part to the wind turbine tower is another part that can have an optimization regarding the number of beams, geometry and holes in the plates and thickness of the plates.

The foundation assembly for the suction caisson in the current study refers to the monopad type, Mono Bucket foundation (MBF), cf. figure 1. Using more legs on a single bucket or more small buckets reduces the embedded scour protection compared to a monopad solution according to Stroescu et al. (2016).

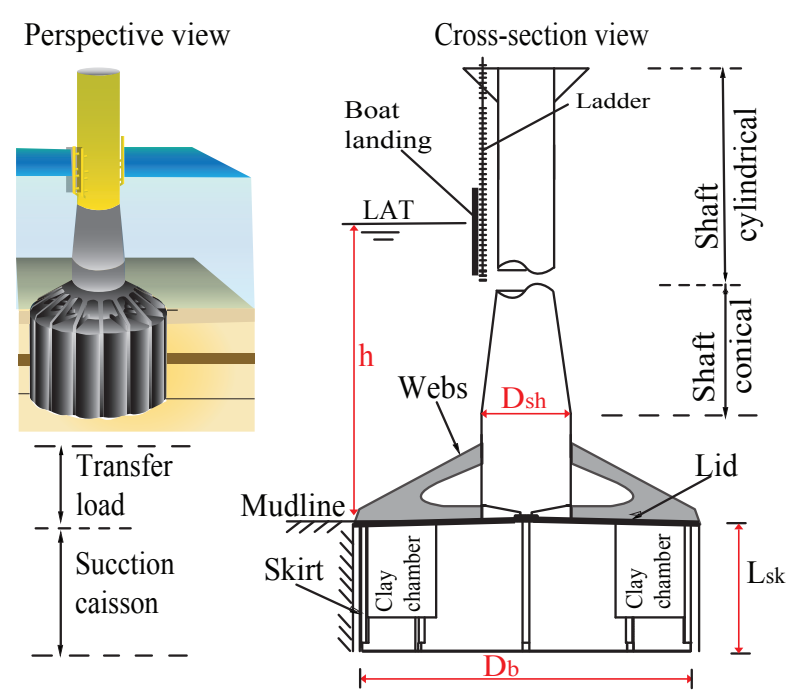

Figure 1: Geometry of Mono Bucket foundation

\section{EXPERIMENTAL ANALYSIS}

The experimental setup is same as Stroescu et al. (2016) and follows similar equipment with Nezhentseva et al. (2014) and Hartvig et al. (2005) in Aalborg University's laboratory flume. The flume arrangement ensures a combination of flows: waves alone, tides alone with both flood and ebb directions, combined waves and tides. The waves generated by the paddle at one end are absorbed in a passive manner by a parabolic beach. The tide flow direction can be switched to propagate either co-directional or opposite to waves direction. The scale in the experiment is 1:90.

The water depth, $h$, equal to $0.32 \mathrm{~cm}$ during the experiment, is kept constant with a $\pm 0.01 \mathrm{~cm}$ variation due to tide flow generation. The experimental analysis uses irregular waves in order to better capture the offshore environmental conditions. The irregular wave generation uses a JONSWAP spectrum with a measurement of the significant wave height, $H_{m 0}$, equal to $0.08 \mathrm{~m} \pm 0.02 \mathrm{~m}$ variation and a peak period, $T_{p}$, of $1.25 \mathrm{~s}$ with variation of $\pm 0.04 \mathrm{~s}$ and a peak enhancement factor, $\gamma$, of 9. The input values are constant during the experiment.

The tide velocities vary in the experiment. Tides and waves form a cycle with one co-directional and opposite propagation of waves and current. In order to counter the turbulences in front of the paddle due to source-pit of tidal current, phenomenon noticed in the first set of experiments, the authors use permeable dispersion boxes(PDB) described in Markus et al. (2015) with own arrangement in the current study. The PDB reduce "boiling" turbulences at the source and ensure a better propagation of the tide currents by placing the channels parallel to the flume flow and perpendicular to the source between 1/2-3/4 the water depth at the PDB location.

An extra PDB sheet is placed toward paddle close to already arranged PDB on top of the tidal source. The extra PDB sheet has same height with PDB and a thickness of $20 \mathrm{~cm}$; the direction of the channels is perpendicular to the flow in the flume. This reduces tidal flow in direction of the paddle and focuses the flow toward the model and ensures the to waves propagate and superimpose with tidal flow in a smoother way. A mirror arrangement for the beach end of the flume reduces the turbulences from the flow and the reflections from waves. Stroescu et al. (2016) shows a model of the test flume.

The sand in the experiment has the density, $\rho_{s}$, equal to $2564 \mathrm{~kg} / \mathrm{m}^{3}$ with the mean grain diameter, $d_{50}$, as $0.184 \mathrm{~mm}$. For the fresh water properties with density, $\rho_{w}$, of $\approx 1000 \mathrm{~kg} / \mathrm{m}^{3}$ the kinematic viscosity, $\nu$ uses a value of $1.3 \cdot 10^{-6} \mathrm{~m}^{2} \mathrm{~s}^{-1}$.

The current study uses the Froude scale for waves and geometry, while for flow/bed stresses since the sand cannot be scaled, it uses Shields number as described in Stroescu et al. (2016).

The experimental analysis uses three models in different arrangements. The base geometrical models described in table 1 have the same diameter for shaft part. Model B is, in fact, Model A with a collar extension. Figure 2 shows the models described in table 1.

Table 1: Description of the models from experimental analysis.

\begin{tabular}{lllll}
\hline Model & & $\mathrm{A}$ & $\mathrm{B}$ & $\mathrm{C}$ \\
\hline Shaft diameter & $D_{s h}$ & $7.5 \mathrm{~cm}$ & $7.5 \mathrm{~cm}$ & $7.5 \mathrm{~cm}$ \\
Caisson diameter & $D_{b}$ & $20 \mathrm{~cm}$ & $20 \mathrm{~cm}$ & $20 \mathrm{~cm}$ \\
No. of TLW & $N_{T W}$ & 9 & 9 & 0 \\
Diameter with collar & $D_{c}$ & $0 \mathrm{~cm}$ & $26 \mathrm{~cm}$ & $0 \mathrm{~cm}$ \\
\hline
\end{tabular}
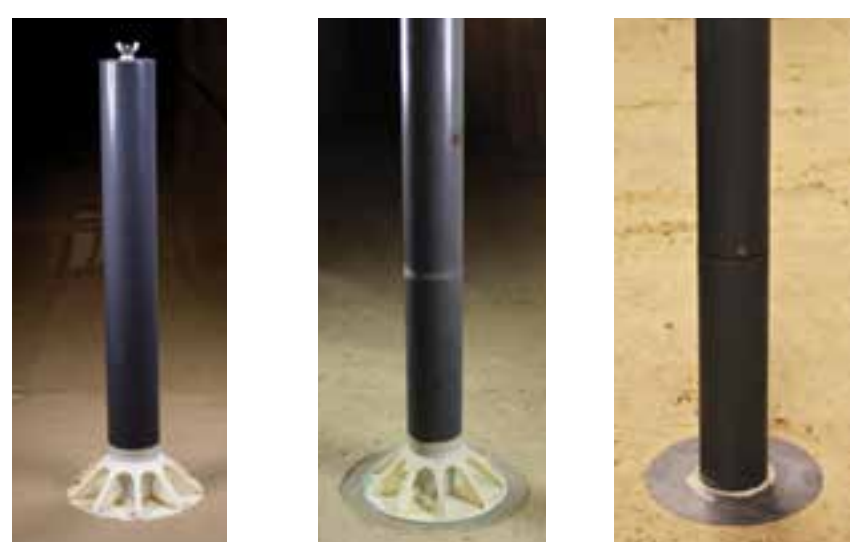

Figure 2: Geometrical models used in the experimental analysis, from left to right model A, B and C. 
In order to assess the influence of load transfer Webs (LTW) and the height between lid and seabed, models $\mathrm{A}$ and $\mathrm{C}$ are placed flushing with seabed as figure 2 shows and with misalignment height, $h_{m i s s}$, of $3 \mathrm{~cm}$. Figure 3 shows misalignment heights for $h_{\text {miss }}$ equal to $3 \mathrm{~cm}$ for models $\mathrm{A}$ and $\mathrm{C}$. The height of the webs is $5 \mathrm{~cm}$, hence, $40 \%$ more than the $h_{m i s s}$ equal to $3 \mathrm{~cm}$ and $80 \%$ more than $h_{\text {miss }}$ equal to $1 \mathrm{~cm}$ which was taken only for model A. The scour is measured with
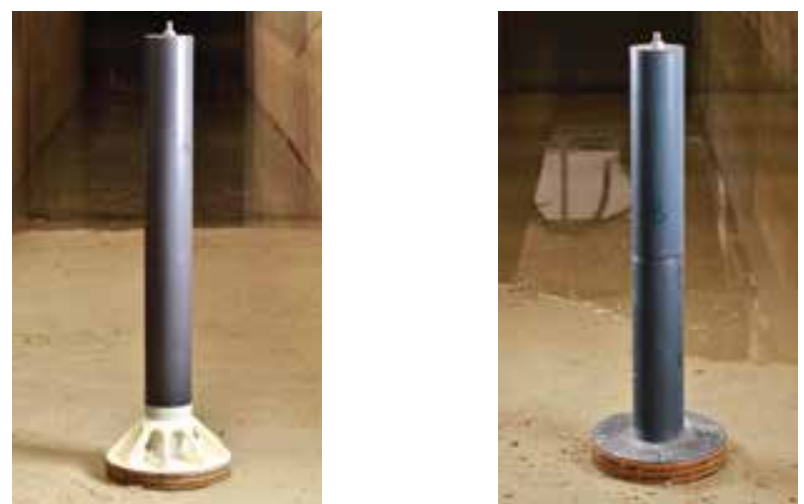

Figure 3: Models, left $\mathrm{A}$ and right $\mathrm{C}$, used in the experimental analysis using variation height with respect to seabed.

a ruler after each flow run to speed up the measuring process while the water was kept in the flume. The scour/backfill was measured with the help of a transparent tube and a photo camera similar to Stroescu et al. (2016). The generated tide cycles create conditions for both scour and backfill to develop. After finishing the last testing cycle for each model, the water was taken out from the flume, underwater measurements were checked and a variance of $\pm 3 \mathrm{~mm}$ was observed.

\section{FIELD SURVEY}

The offshore results for scour measurements around MBF are collected from the North Sea. The scour data characterizes the results for three foundations supporting Met. Masts. Out of the three, one, from Horns Rev II site (HRII) was successfully fully decommissioned in 2015 after completing the intended six years of life time design as stated in Universal Foundation (2015). This action has a great significance that raises the environmental impact expectations to a higher level for all type of wind turbine offshore foundations. The other two foundations supporting Met. Masts, as well, are closer to the UK shores in Dogger Bank site from the North Sea.

The installation process was supervised using an underwater remotely operated vehicle (ROV) which enabled the visual recording of scour development. The records are available for the two Dogger Bank installations, East and West locations (DBE and DBW). Figure 4 shows the three foundations before installation. For HRII the scour results are available only for the scour survey after the installation. The recordings refer only to scour development not to the flow
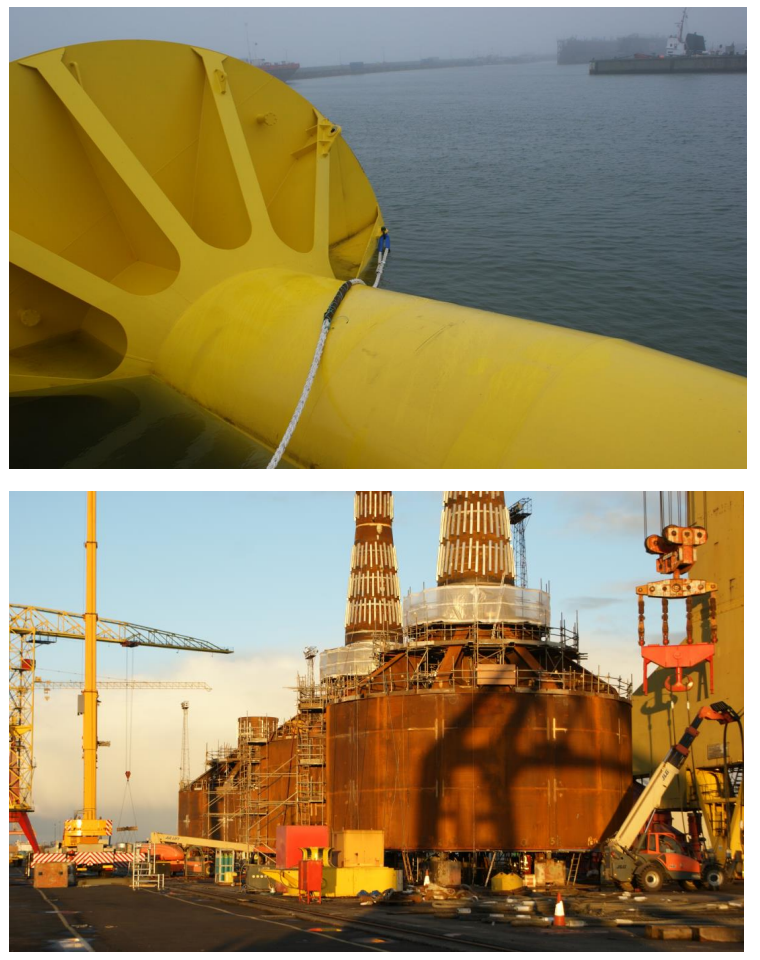

Figure 4: MBF models. Top: HRII; Bottom: DBE and DBW.

speeds. A description is given in Stroescu et al. (2016) for all three sites and the foundations. Table 2 shows some of the sites and foundation geometry properties for the three foundations. There are no recorded flow measurements. Moreover, a variance of the scour depth with $\pm 10 \mathrm{~cm}$ due to visual measurements is expected before the final scour inspection after finishing installation for DBE and DBW. In the case of DBE

Table 2: Environmental properties of the sites and geometry of foundations for the installed MBF.

\begin{tabular}{|c|c|c|c|c|}
\hline & & DBE & DBW & HRII \\
\hline Install. duration & $T_{\text {inst }}$ & $6 \mathrm{~h}$ & $7.5 \mathrm{~h}$ & $8 \mathrm{~h}$ \\
\hline Skirt length & $L_{s k}$ & $7.5 \mathrm{~m}$ & $7.5 \mathrm{~m}$ & $6 \mathrm{~m}$ \\
\hline Diameter caisson & $D_{b}$ & $15 \mathrm{~m}$ & $15 \mathrm{~m}$ & $12 \mathrm{~m}$ \\
\hline Diameter shaft & $D_{s h}$ & $4 \mathrm{~m}$ & $4 \mathrm{~m}$ & $4.5 \mathrm{~m}$ \\
\hline Transfer webs no. & $N_{T W}$ & 9 & 9 & 12 \\
\hline Seabed alignment & $h_{m i s s}$ & $0.3 \mathrm{~m}$ & $0.3 \mathrm{~m}$ & $0.6 \mathrm{~m}$ \\
\hline Mean grain diam. & $d_{50}$ & $0.13 \mathrm{~mm}$ & $0.13 \mathrm{~mm}$ & $0.4 \mathrm{~mm}$ \\
\hline Wave height & $H_{s, 1 y}$ & $6 \mathrm{~m}$ & $6 \mathrm{~m}$ & $4 \mathrm{~m}$ \\
\hline Peak period & $T_{p}$ & $16 \mathrm{~s}$ & $15 \mathrm{~s}$ & $12 \mathrm{~s}$ \\
\hline Install. Flow vel. & $U_{c, i n s}$ & $0.5 \mathrm{~m} / \mathrm{s}$ & $0.5 \mathrm{~m} / \mathrm{s}$ & $1.5 \mathrm{~m} / \mathrm{s}$ \\
\hline
\end{tabular}

and DBW the sand density is $\rho_{s}$ equal to $2730 \mathrm{~kg} / \mathrm{m}^{3}$ while on HRII $\rho_{s}=2600 \mathrm{~kg} / \mathrm{m}^{3}$. The water density on all three sites is approximately $1030 \mathrm{~kg} / \mathrm{m}^{3}$. The flow velocity during installation was approximately $0.5 \mathrm{~m} / \mathrm{s}$ for DBE and DBW. The maximum flow velocity recorded for HRII was $1.6 \mathrm{~m} / \mathrm{s}$. The installation starts if the forecast shows windows with $H_{s}$ below $1.2 \mathrm{~m}$. Thus, the installation conditions on all three sites were tide dominating. Moreover, the one-year return flow velocities for DBE and DBW are $0.8 \mathrm{~m} / \mathrm{s}$ and $0.9 \mathrm{~m} / \mathrm{s}$ while the one-year mean values for the site are $0.2 \mathrm{~m} / \mathrm{s}$ and $0.3 \mathrm{~m} / \mathrm{s}$. For the HRII, the design conditions are not provided but the one-year mean is $0.5 \mathrm{~m} / \mathrm{s}$. 


\section{$4.1 \quad$ Field measurements}

Using the images recorded by the ROV during the MBF installation, several phenomena were noticed. In both DBE and DBW locations during touch down stage, the first $10-20 \mathrm{~cm}$ layer of seabed was moved around until the actual penetration under own weight started. This is related to the crane movements up and down and spinning in order to master the foundation in the target installation position and thus, generating an initial scour around foundation.

The second observation refers to the starting of the active installation when suction is applied in the caisson to create differential pressure that ensures the soil penetration. At this point there is a likelihood for sediment suspension at the surface of seabed close to the skirt walls and to be flushed away. This is caused by a liquefaction of the upper soil in places where pipping channels could form. The flow from outside caisson inside the caisson might not be strong to form a piping channel to stop installation but it can destabilize the grains at the surface, for the first part of the soil layer when suction is active. This process generates usually a significant scour hole within the first one hour of active installation. This interaction between scour and installation flow can speed up the formation of piping channels.

The third observation refers while flow encounters the skirt wall, the difference in the permeability between sand and steel, allows to sand particles to be suspended due to pressure gradient, similar to the process of scour around monopiles. This lead to an initial deep, steep and small cross-size scour depth that later extends its size but decreases in depth.

The scour holes usually develop for DBE and DBW at the intersection of the shells which form the skirt which corresponds to each TLW. This geometrical feature is neither available for HRII nor does the installation information exist for HRII to assign this to observations available for large diameter structures. Moreover, these holes are few and their development increases with penetration.

Ranch (1980) shows symmetry at the maximum scour holes for large diameters in all flow approaches, while in the MBF case there is small symmetry and the maximum depth is rather singularly positioned. This could be due to the interaction with the flow in a different manner for a multi-shell shape than circular or square. However, the maximum scour recorded during installation and from the other surveys for DBE and DBW of $0.047-0.066 D_{b}$ gets however closer to the estimated value of $0.064 D_{b}$ presented by Ranch (1980) for combined tides and waves. Advancing with installation depth limits, the skirt exposure and the influence of LTW becomes more significant and the scour holes become larger in numbers and in spreading. Looking at the survey images after installation completes, the scour holes close to LTW are present for DBE, DBW and HRII.

Figure 5 sketches the scour holes observed and their distribution after installation (first and second images from the left, in red line) for DBE and DBW. The blue line shows the scour survey results from a second measurement campaign which took place shortly after installation. However, for DBE the second campaign coincides with the installation of DBW, thus the latter has no result.
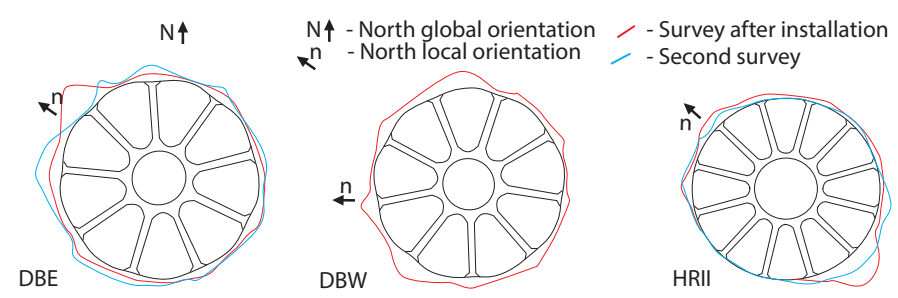

Figure 5: Scour survey from field measurements around offshore installed MBF.

The ROV measured several times around foundations during installation; however, most of the time it recorded on one position. These positions had the notations $\mathrm{N}, \mathrm{E}, \mathrm{S}, \mathrm{W}$ with a $90^{\circ}$ angle between, and refer to a global system of coordinates. Preserved through the rest of results presentation. The local coordinate orientation is denoted with $n$ for north in figure 5, which is helpful when comparing with the field measurements results from Stroescu et al. (2016) referring to latest survey for same foundations. The development of scour outside N,E,S and W points is referred in combination with the main positions.

In figure 6 the measurements for each direction show scour/backfill development. The results are given with respect to time between touch down of the foundation and the end of installation.

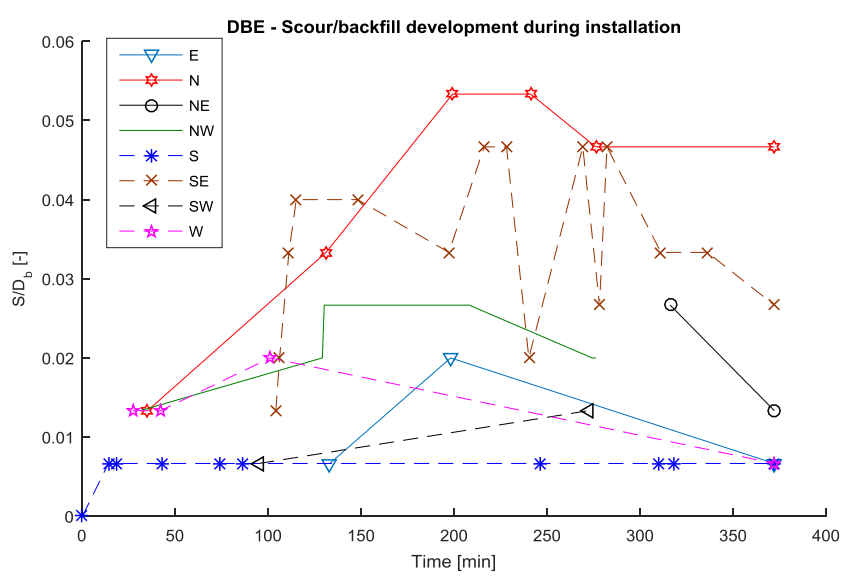

Figure 6: Scour survey during installation for DBE.

When looking at the second scour survey for DBE (figure 5, blue line) one can see compared to the initial scour depth (figure 5, red line and the northern direction in figure 6) the hole was completely backed filled. However, what figure 5 shows is the fact that the global scour develops since $h_{m i s s}$ increases to 
$0.125 D_{s h}(0.5 \mathrm{~m})$ from $0.05-0.075 D_{s h}(0.20 .3 \mathrm{~m})$. This also agrees with the results presented in Stroescu et al. (2016) related to the last survey on the site arrangement. Thus, the scour development has small variations between measurements with values captured well by the survey made until now.

For the DBW case, a small dune is formed during installation, and unlike DBE the flow is stronger from the beginning and more sediments can be seen in the recorded material. Moreover, the scour in this case starts with a concave shape. Hence, the scour hole bottom is not close to the foundation. When the installation is completed the hole shape drifts into a triangular one, with the maximum depth next to the skirt. Figure 7 shows the measurement of scour/backfill with fewer points for the other directions as there are fewer spins with the ROV around MBF. The WS scour hole extends and becomes the same as W. In the $\mathrm{S}$ direction no scour is seen at the end of installation.

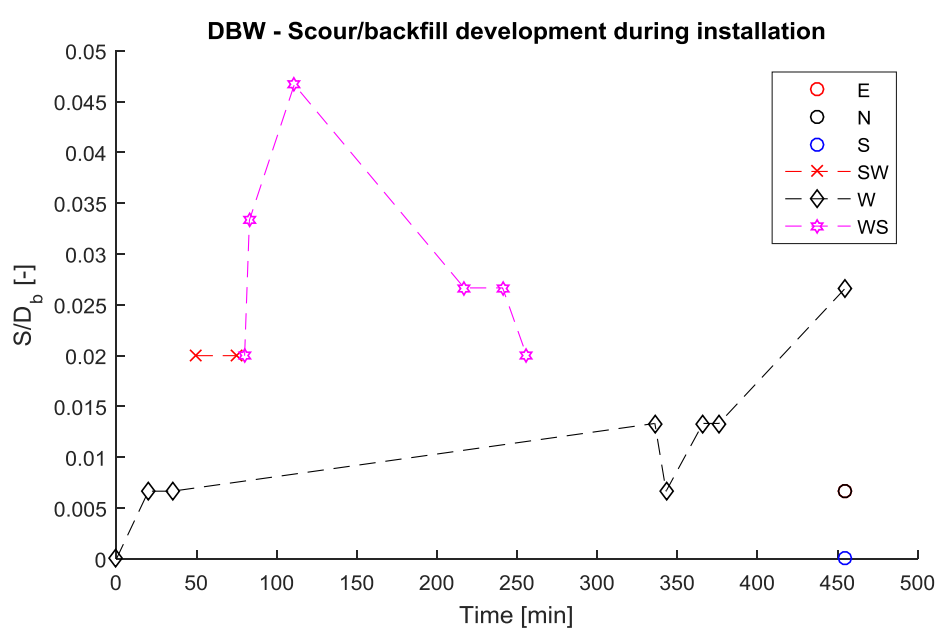

Figure 7: Scour survey during installation for DBW.

From figure 8 the backfill can be associated with the reduction of exposed skirt. However, this reduction is small, which seems to agree also with the remarks from Hartvig et al. (2005) and Petersen et al. (2014) related to the longer time needed for backfill.

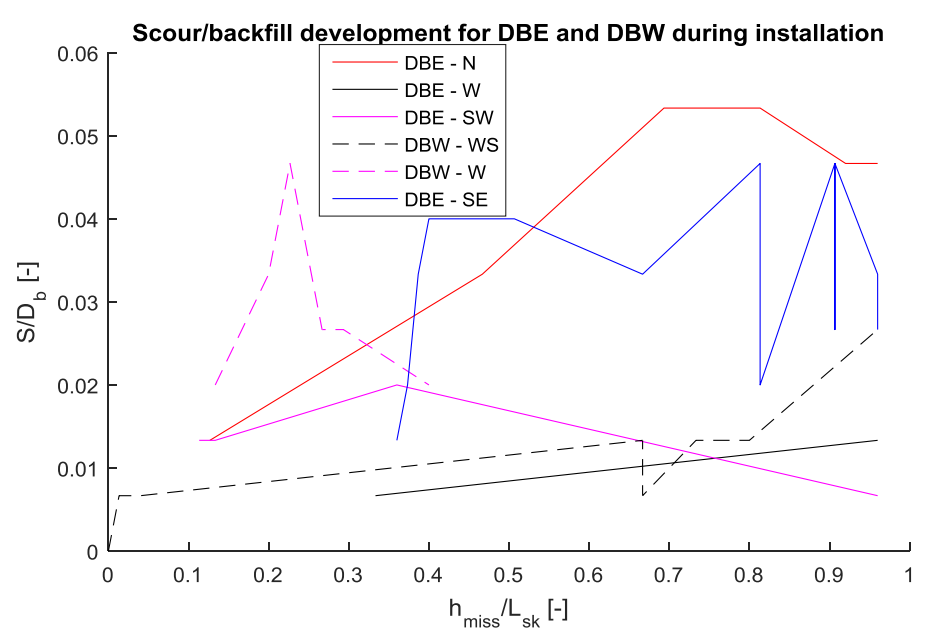

Figure 8: Scour survey during installation for DBE and DBW with respect to skirt penetration.
For HRII the scour measurements after installation and in the second survey show a significant backfill and the same correlation between scour holes and LTW.

\subsection{Experimental measurements}

The interpretation of the experimental measurements is similar to the one presented in Stroescu et al. (2016) with respect to Shields parameter, $\theta$, and critical Shields parameter, $\theta_{c r}$; calculation which follows the methodology from Soulsby (1997). The scour values are presented as the maximum records regardless direction after each test. In Stroescu et al. (2016) the scour results are given as average of one cycle; hence, the latter has smoother results.

The assessment for combined tide and wave velocity, $U_{c w}$, is similar to Hartvig et al. (2005) and Petersen et al. (2014) for irregular waves in which the bed shear stress for current is found using ColebrookWhite formulation. Thus, the variance spectrum for surface elevations of the recorded test was transformed to orbital velocity at same depth as the measured mean velocity, assuming wave linear theory. The variance spectrum for water elevations differs in shape compared with the velocity. However, the $U_{m 0}$ resulting from transformation of the surface elevation and the directed measured velocity varies slightly with less than $0.04 \mathrm{~m} / \mathrm{s}$. Thus, the flow regime is still dominated by tides. These methods are adopted since most of the recent work related to scour/backfill development in tides combined with waves use these approaches.

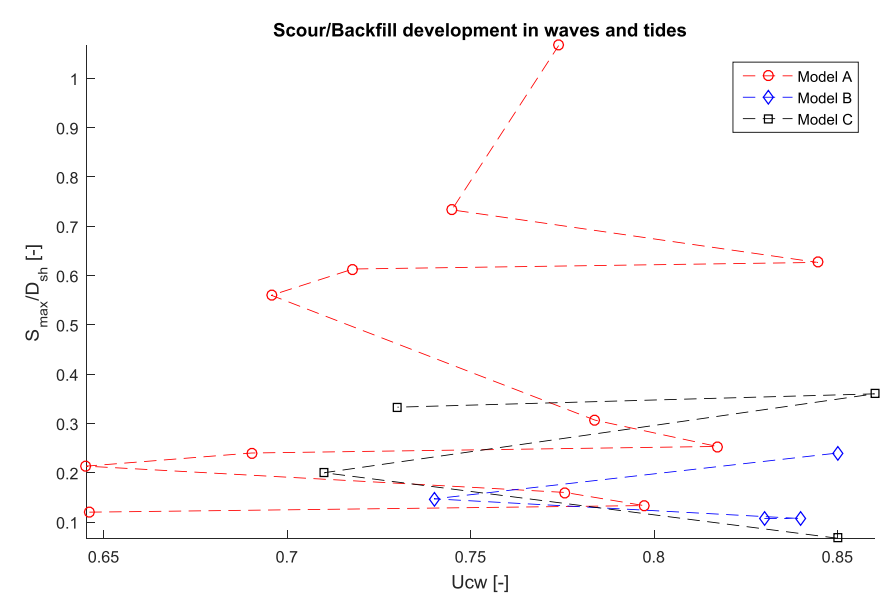

Figure 9: Scour measurements in combined tides and waves for LTW analysis with respect to $U_{c w}$.

The results in figure 9 show the flow regime in the predominant tidal conditions. Moreover, it shows that MBF can handle several severe consecutive tidal cycles before reaching scour depths in same range as a monopile assuming a diameter of the pile equal to shaft diameter. The resistance to these cycles, like in Stroescu et al. (2016), depends on the diameter ratio $D_{b} / D_{s h}$ but also on the presence of the webs. 
Model C, black line, shows larger initial scour formation with more backfill in more severe tidal conditions. Model B is less sensitive to scour as it combines both a larger ratio $D_{b} / D_{s h}$ and the LTW are not reaching the end of the lid.

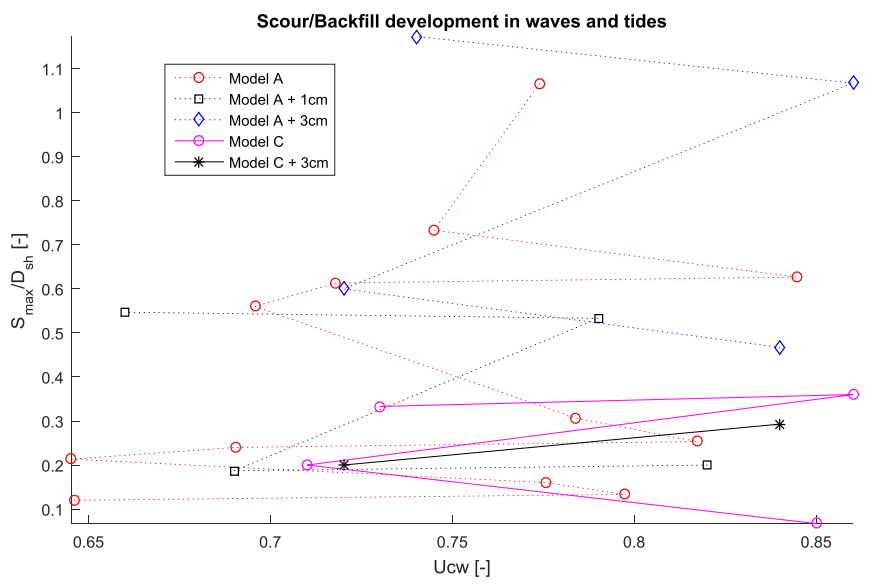

Figure 10: Scour measurements in combined tides and waves for $h_{m i s s}$ analysis with respect to $U_{c w}$.

The misalignment plays a big role in scour development. Figure 10 shows that flow regimes with predominate tides experiences with higher $h_{\text {miss }}$, larger scour and MBF support fewer extreme cycles. Moreover, the LTW interacts with flow generating scour even in early stages of the installations which agrees with the observations from the field measurements. Between model $\mathrm{C}$ and model $\mathrm{C}+3 \mathrm{~cm}$, there is a large difference in scour development which reiterates the misalignment importances. During installation the closer the lid is to the seabed, the less scour will develop. Indeed, HRII results show that with up to 0.5$0.6 \mathrm{~m}$ of misalignment height the scour does not grow rapidly and significant backfill can be experienced.

In Stroescu et al. (2016) the waves alone have an importance with respect to reshaping the seabed while the effective scour development is insignificant mostlikely due to diffraction since is not the case for monopiles. Based on this remark, the data shown in figures 9-10 is presented in function of Shields parameter.

Figure 11 illustrates in good agreement with de Sonneville et al. (2010) that the collars reduce scour developments. Moreover, the influence of the LTW in scour development is smaller if they do not reach the end of the lid, and if the $D_{b} / D_{s h}$ ratio is large then few benefits can be seen, as the scour produced by model $\mathrm{C}$ is larger than model $\mathrm{B}$. This might be due to the local turbulences produced on the lid by the LTW that prevent formation of lee-wake vortices due to shaft presence and ensure the formation of the counter-rotating vortices observed in the case of scour protected monopiles by Petersen et al. (2014) in the process of edge scour.

The correlation of tide intensity and the misalignment height between lid and seabed shows the large

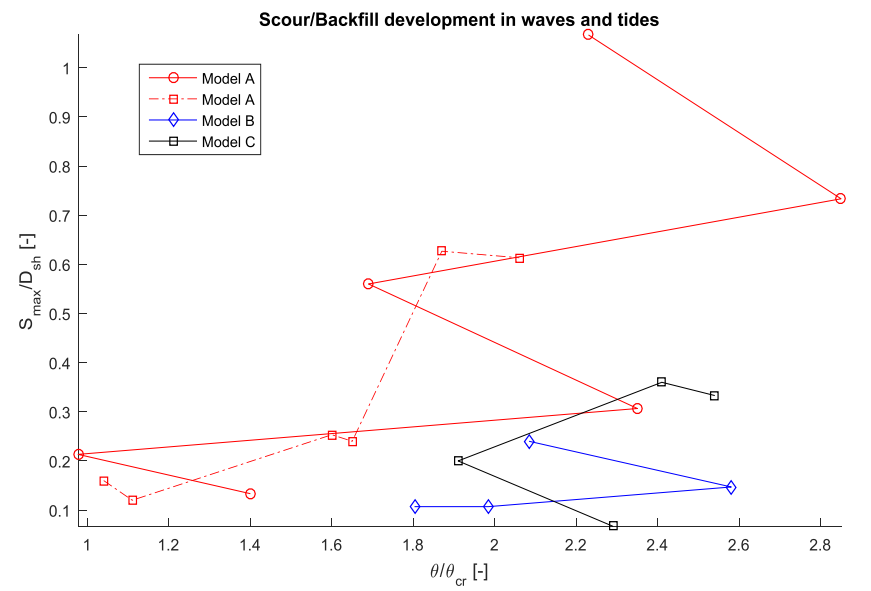

Figure 11: Scour measurements in combined tides and waves for LTW analysis with respect to $\theta / \theta_{c r}$.

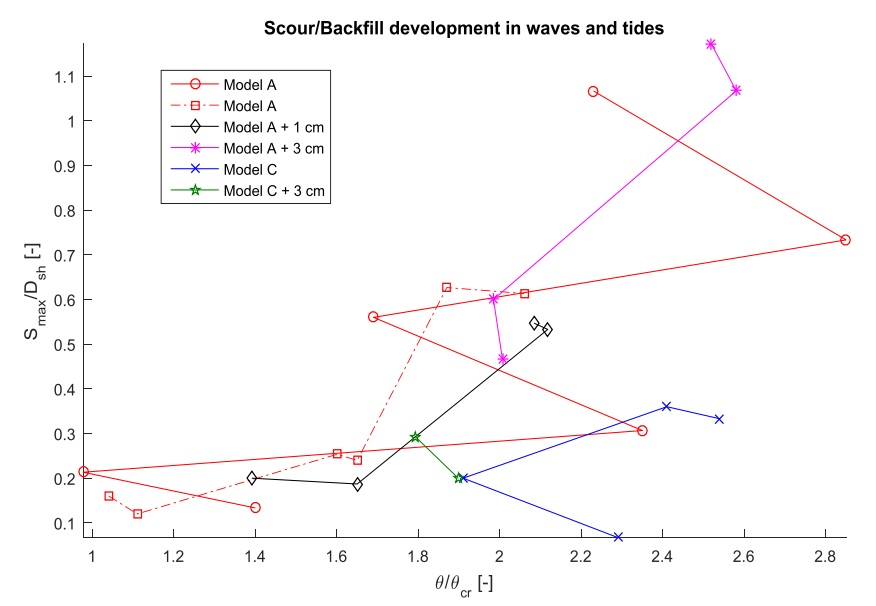

Figure 12: Scour measurements in combined tides and waves for $h_{m i s s}$ analysis with respect to $\theta / \theta_{c r}$.

susceptibility to scour development and the nonbeneficial LTW presence on the lid when the misalignment height is high.

\section{CONCLUSIONS}

If the installation takes place in areas with strong tides, either seabed preparation is required regardless of the foundation solution or a contingency plan to refill the scour holes. This is not the case in conditions like the ones from Dogger Bank and Horns Rev II for MBF. A correlation of installation with the expected tidal velocity can reduce initial scour as the LTW acts as a blockage factor like the skirt wall, thus avoiding exposing the skirt and the webs during high intensity of tides.

The LTW and other irregularities in/on the lid have a beneficial effect on reducing scour and increasing backfill. The scour can be reduced if the height of the LTW is small and if there is sufficient distance between end of the lid and the end of LTW.

For the scour estimations considering the current LTW design, the total blockage factor should be decreased when accounting with the misalignment height; as it does not have the same effect like a cylindrical closed box with $40 \%$ reduced height of the 
LTW and like the scour protection height for scour protected monopiles.

In general there is good agreement between the observed effect on the field measurements and the experimental results. Although the experimental conditions are not simulating the conditions from the considered sites for field measurement, the variations are small and the effects are similar. Moreover, these results enforce the embedded properties of the MBF against scour development and the possibility to have foundations for offshore wind turbines with MBF and no scour protection.

A recommendation for $\mathrm{MBF}$ design is to extend the lids diameter to reduce the negative effects of the LTW. While, the other recommendation is implicit to the success of the installation and refers to a minimized misalignment height. The combinations of the LTW with $0.2-0.3 \mathrm{~m}$ of misalignment between seabed and lid results in generation of another $0.3 \mathrm{~m}$ of global scour for DBE. Meanwhile, the larger local scour hole was completely backfilled.

Field measurements are rare and of great value for validating scale tests. Therefore, the good agreement between data from the Dogger Bank offshore site at prototype scale and the flume experiments at small scale is very important in order to understand also model test data in general as well. Hence, the field measurements provide confidence in small-scale data.

\section{REFERENCES}

de Sonneville, B., D. Rudolph, \& R. T.C. (2010). Scour reduction by collars around offshore monopiles. ICSE-5, 460-470.

Hartvig, P., J. Thomsen, P. Frigaard, \& T. Andersen (2005). Experimental study of the development of scour and backfilling. Coastal Engineering Journal 52, 157-194.

Markus, D., M. M. Jakobsen, K. Bletzinger, \& P. Frigaard (2015). Damping of unwanted turbulence in wavecurrent experiments. Coastal Engineering - 96, 38-40.

Nezhentseva, A., L. Andersen, T. Andersen, E. V. Sø rensen, \& L. B. Ibsen (2014). Design of transition pieces for bucket foundations for offshore wind turbines. DCE Thesis 42.

Petersen, T., B. Sumer, J. Fredse, D. Fuhrman, , \& E. Christensen (2014). Scour around offshore wind turbine foundations. Phd Thesis.

Ranch, P. (1980). The potential for scour around large objects. Scour Prevention Techniques around Offshore Structures, 41-53.

Soulsby, R. (1997). Dynamic of marine sands.

Stroescu, I., P. Frigaard, \& M. Fejerskov (2016). Scour development around bucket foundations. International Journal of Offshore and Polar Engineering IJOPE-26(1), 57-64.

Universal Foundation (2015). First Mono Bucket is decommissioned after 6 years of service. http://universalfoundation.com/media/news/ \#100319. 